\title{
ESTUDO DE VIABILIDADE ECONÔMICA PARA IMPLANTAÇÃO DE SISTEMA DE ARMAZENAGEM E CLASSIFICAÇÃO DE MAÇÃ EM SANTA CATARINA ${ }^{1}$
}

\author{
Silvio Antônio Ferraz Cário ${ }^{2}$ \\ Fernando Seabra ${ }^{3}$ \\ José Antonio Nicolau ${ }^{4}$ \\ Flávio José Simioni ${ }^{5}$ \\ Cleiton Cardoso Bittencourt ${ }^{6}$
}

\begin{abstract}
Resumo: $\mathrm{O}$ artigo trata de um estudo de viabilidade econômico-financeira visando à implantação de equipamentos de câmaras frias para armazenagem e classificação de maçã na região Serrana de Santa Catarina. Nesta região existe um déficit de capacidade de armazenamento da ordem de $52 \%$ da quantidade produzida. Foram projetados investimentos em três tamanhos de estabelecimentos que expandem a capacidade de armazenamento e classificação em $50 \%$, cujos investimentos se situam próximos de R $\$$ 67 milhões para um horizonte de 20 anos. O VPL foi positivo para ocupações acima de $60 \%$ e as TIRs se situam acima de $20 \%$ para um grau de utilização da capacidade instalada de $100 \%$ e entre 15 e $20 \%$ para um grau de utilização de $80 \%$. Os pontos de equilíbrio alcançados se situam em um grau de utilização da capacidade entre $43 \%$ para o maior tamanho e $57 \%$ para o menor tamanho.
\end{abstract}

Palavras-chave: Maçã. Cadeia Produtiva. Armazenamento.

1 Recebido em: 24/05/212; Aceito em: 3/09/2012.

2 Professor Doutor do Departamento de Ciências Econômicas da Universidade Federal de Santa Catarina (UFSC), E-mail: fecario@yahoo.com.br,

3 Professor Doutor do Departamento de Ciências Econômicas da Universidade Federal de Santa Catarina (UFSC). E-mail: seabra@cse.ufsc.br

4 Professor Doutor do Departamento de Ciências Econômicas da Universidade Federal de Santa Catarina (UFSC). E-mail:nicolau@cse.ufsc.br

5 Professor Doutor da Universidade do Estado de Santa Catarina (UDESC). E-mail: fjsimioni@hotmail.com

6 Professor da Universidade do Grande Rio (UNIGRANRIO).. E-mail: cleitonbittencourt@yahoo.com.br 
Abstract: This paper deals with the economic and financial feasibility of a project to implement cold storage and classification facilities for apple production in Serrana region of Santa Catarina (Brazil). In that region there is a current storage deficit of around $52 \%$ of total local production. In our feasibility project, we consider three different amounts of investments which result in an increase of $50 \%$ in local storage and classification capacity and amount approximately $\mathrm{R} \$ 67$ million in a time span of 20 years. The NPV was positive for occupations up $60 \%$ and the IRR lies over $20 \%$ per year assuming a usage of installed capacity of $100 \%$ and between 15 and $20 \%$ for a utilization rate of $80 \%$. Finally, the breakeven point for the investments indicates a minimum use of total capacity of $43 \%$ for the larger plant and $57 \%$ for the smaller plant.

Keywords: Apple. Production Chain. Storage Facilities.

\section{Introdução}

O estado de Santa Catarina é o maior produtor nacional de maçã, tendo a produção da safra de 2010/2011 alcançado cerca de 690 mil toneladas. A produção está concentrada em duas importantes regiões: meio oeste (onde se destaca o Município de Fraiburgo) e Serrana (com destaque para o município de São Joaquim). Enquanto no meio oeste a pomicultura é de perfil empresarial, na região de São Joaquim há o predomínio de pequenos agricultores que utilizam mão de obra familiar, e a comercialização das frutas é, em parte, realizada por cooperativas (SIMIONI; PEREIRA, 2001, 2004).

A região serrana responde por mais de $53 \%$ da produção estadual e ainda possui condições climáticas adequadas e disponibilidade de área para expansão da produção, porém com solo de maior declividade e pedregosidade, dificultando sua mecanização. Esta região congrega 1.815 fruticultores com área média de 5,9 hectares, sendo um grande número de unidades produtivas com área de 0,5 a 2,5 ha. Segundo estimativa da EPAGRI (2008), cerca de 70\% dos produtores de maçã carece de estrutura adequada de produção e de comercialização, e cerca de $60 \%$ do volume de frutas comercializadas in natura a granel são destinadas para outras regiões, sobretudo para Fraiburgo (SC) e Vacaria (RS). 
De acordo com dados de Bittencourt (2008), Santa Catarina apresenta decréscimo da capacidade de armazenagem em relação à produção, passando de 74,6\% em 1999 para 65,0\% em 2007. A maior capacidade de armazenamento encontra-se localizada na região de Fraiburgo, com $58,7 \%$ da produção total, equivalente a 195 mil toneladas, das quais $67 \%$ são equipadas com sistema de atmosfera controlada. Já na região de São Joaquim, a capacidade de armazenagem é 41,3\% da produção (cerca de 140 mil toneladas), com maior proporção da armazenagem convencional.

Considerando uma taxa de crescimento da produção de maçã de cerca de $4 \%$ ao ano e uma capacidade de armazenagem ideal na ordem de $80 \%$ da produção, há necessidade de investimentos em câmaras de conservação para a região Serrana superior a 120 mil toneladas (EPAGRI, 2008). Entre os municípios produtores, a maior necessidade está em São Joaquim (48 mil toneladas) e Bom Jardim da Serra (25 mil toneladas), correspondendo a cerca de $60 \%$ da necessidade total.

Corrobora a ocorrência deste processo a inexistência de um sistema de armazenamento e processamento voltado para atender os produtores não organizados de maçã da região. Tais produtores agem individualmente deixando a produção à mercê das forças de mercado, cujas características de perecibilidade do produto e do poder de negociação dos compradores os tornam reféns de atitudes oportunistas (BARBOSA et al., 2006).

Diante da expansão da oferta de maçã na região e da falta de capacidade de armazenamento da produção, pequenos produtores se deparam com preços de vendas aquém de seu real valor, sobretudo nos momentos de safra. Apesar da média a alta rentabilidade obtida no cultivo da maçã, apontada por Guth et al. (2010), Kreuz et al. (2005) e Kreuz, Souza e Petri (2006), a deficiência de armazenagem pode comprometer a viabilidade da atividade de muitos pequenos pomicultores.

Diante deste contexto, objetiva-se analisar as condições de instalação e viabilidade econômica de uma estrutura de armazenamento e de classificação da maçã a ser gerida por cooperativa de produtores, na 
região Serrana de Santa Catarina, com vistas a oferecer alternativa de comercialização mais rentável aos pequenos produtores.

\section{Metodologia}

Os dados para a realização do estudo foram obtidos de fonte primária, em janeiro de 2010, na Cooperativa Regional Agropecuária Serrana (Cooperserra), fornecedores de equipamentos (máquina de classificação e câmaras frias) e no mercado financeiro. Também foram utilizados dados de fontes secundárias, advindos de relatórios da Empresa de Pesquisa Agropecuária e Extensão Rural de Santa Catarina (EPAGRI) e de relatórios de mercado.

O estudo considerou, em primeiro lugar, o tamanho e localização das unidades de armazenamento e classificação. O segundo aspecto foi a identificação dos preços de venda da maçã ao mercado, os preços a serem pagos aos produtores e a estrutura de investimentos e de custos. Finalmente, foram identificadas as fontes de financiamento e analisadas as condições da viabilidade econômica dos empreendimentos.

A definição do número e local das unidades de armazenagem e beneficiamento de maçã considerou diversos aspectos, como distribuição geográfica da produção, infraestrutura local e disponibilidade atual de armazenagem. Algumas condições foram elencadas como necessárias, tais como as estradas com pavimento asfáltico em boas condições até a entrada do terreno, proximidade de núcleos urbanos com disponibilidade de mão de obra qualificada na área de técnicas de armazenagem e acesso à rede elétrica trifásica.

Atendidas as precondições quanto à localização, às decisões técnicas relacionadas ao tamanho e ao cronograma dos empreendimentos, segundo o seu tipo, a armazenagem e a armazenagem com classificação obedeceram aos seguintes critérios: a) tamanho do excedente de produção atual e projetado em relação à capacidade de armazenagem e 
de classificação do município ou localidade; b) número de produtores não cooperados na região candidata a sediar a unidade de armazenagem; e c) localização estratégica, como acesso a importantes rodovias e sinergias com outras atividades, como agroindústria, polos industriais e turismo.

Para a definição do porte dos empreendimentos, foram considerados três principais aspectos a respeito da tecnologia industrial no setor de armazenamento e classificação da maçã: dinâmica tecnológica, modularidade dos equipamentos e logística interna. Em relação à tecnologia, merecem destaque os estudos experimentais referidos na literatura sobre o uso de diferentes gases e insumos químicos integrantes da atmosfera controlada. Por sua vez, a tecnologia de classificação da maçã tem sua trajetória marcada pela introdução de instrumentos informatizados para classificação, mas ainda combinados com o amplo uso da classificação manual. Considerou-se que a integração de armazenamento e classificação, numa única unidade, economiza custos relacionados à logística, e pelo fato de inexistirem substanciais ganhos de escala no equipamento de classificação, adotou-se no estudo a organização de packing houses integradas e de porte variado, de acordo com o volume de produção de maçã nas diferentes localidades. Assim, foram realizados estudos de viabilidade para três tamanhos de empreendimento: 10 mil t/ano, 20 mil t/ano e 30 mil t/ano.

Para realização da análise da viabilidade econômica, foi utilizada a experiência de uma cooperativa de produtores que atua no município de São Joaquim (Cooperserra). Assim, foram utilizados dados de preços e custos operacionais dessa cooperativa nos últimos anos de modo a definir os valores para os novos empreendimentos. Quanto aos equipamentos e instalações, foram feitos levantamentos de preços junto a fornecedores tradicionais da região. Quanto aos preços de venda, foi feita análise da sazonalidade e dos valores por categoria de fruta, apurandose um preço médio de referência para efeito de estimar a receita dos empreendimentos. No que se refere ao preço de compra ou ao custo da matéria-prima, foram tomados por referência os preços praticados pela Cooperserra junto a seus cooperados, com acréscimo de $3 \%$ por quebra 
de peso. Os custos fixos e variáveis foram também definidos com base na experiência dessa cooperativa, apurados a partir da especificação do número de pessoas a serem empregadas, veículos, consumo de energia, gastos com manutenção etc.

Para a determinação do valor dos investimentos, foram obtidas informações de fornecedores e cooperativas quanto à especificação técnica dos equipamentos, tamanho e preços. Também conforme a experiência de empreendimentos existentes, utilizou-se o horizonte de tempo de 20 anos para efeito da análise da viabilidade, tempo esse correspondente à vida útil dos principais equipamentos (câmaras frias e máquina de classificação). Além desse parâmetro, há a necessidade de reposição de veículos (a cada cinco anos) e de empilhadeiras (a cada dez anos). Por outro lado, foi arbitrada vida útil de 40 anos para as estruturas pré-moldadas dos galpões, uma vez que têm duração indefinida, segundo informações dos fornecedores. Por fim, a infraestrutura de terreno, terraplenagem e ligação elétrica externa foram assumidas como sendo fornecidas pelo poder público local, dado o interesse por estimular o projeto.

A análise da viabilidade econômico-financeira dos empreendimentos compreendeu, além de toda a especificação dos empreendimentos, a estimativa do Valor Presente Líquido (VPL) e da Taxa Interna de Retorno (TIR) para os três tamanhos de empreendimento, com simulações em termos de ocupação da capacidade instalada e de preços de venda.

O VPL é obtido calculando-se o Valor Presente (VP) dos Fluxos de Caixa (FC), empregando-se uma taxa de desconto (k), e do somatório diminui-se o investimento inicial $\left(\mathrm{I}_{0}\right)$ e os demais investimentos (I) que são realizados ao longo de cada período ( $\mathrm{t}$ ) do projeto, também descontados a taxa $\mathrm{k}$, conforme a equação:

$$
V P L=\left[\sum_{t=1}^{n} \frac{F C_{t}}{(1+k)^{t}}\right]-\left[I_{0}+\sum_{t=1}^{n} \frac{I_{t}}{(1+k)^{t}}\right]
$$


Como critério de decisão, projetos que apresentam VPL $\geq$ zero são viáveis, ou seja, se o VPL obtido a determinada taxa $\mathrm{k}$ for nulo, significa que o capital é remunerado exatamente à taxa $\mathrm{k}$. Se o VPL for positivo, significa que há uma remuneração superior à taxa $\mathrm{k}$ estabelecida, enquanto um VPL negativo indica um retorno inferior à taxa mínima $(\mathrm{k})$ requerida para o investimento. O VPL expressa o resultado econômico, isto é, o valor atualizado do projeto de investimento ou a "massa de lucros", como mencionam Galesne et al. (1999). Para que o indicador expresse um resultado coerente, os autores chamam a atenção para a apropriada definição da taxa de desconto, que está associada ao custo de oportunidade do capital, tendo sido arbitrada taxa atrativa de $10 \%$ ao ano. O VPL pressupõe, implicitamente, que seus fluxos intermediários de caixa devem ser reinvestidos à taxa de desconto utilizada na avaliação do investimento.

A TIR é a taxa de desconto que zera o VPL. Se a TIR for maior que a TMA, é viável o projeto (CASAROTTO FILHO; KOPITTKE, 2010). Sua estimativa consiste em encontrar uma taxa k que zere o VPL, sendo necessária planilha eletrônica para sua determinação.

De acordo com Abreu Filho et al. (2006, p. 89), a TIR é um dos critérios mais controversos, podendo levar a conclusões equivocadas. Os principais problemas que a TIR apresenta são: a) não consegue diferenciar projetos que dão prejuízo dos que dão lucro; b) para fluxos de caixa em que o saldo apresenta mais de uma inversão de sinal (não puros), pode-se verificar a existência de múltiplas TIR; e c) em determinadas situações, a TIR poderá indicar a preferência por um projeto enquanto o VPL, por outro. Neste último caso, ao comparar a evolução do VPL de dois projetos segundo diferentes taxas de desconto, podem-se verificar curvas de diferentes formatos em que a viabilidade pode ser alterada conforme a taxa de desconto utilizada, tendo na intersecção de Fischer a identificação da taxa de desconto que apresenta o mesmo VPL de ambos os projetos. Outro aspecto a ressaltar é que a TIR somente será verdadeira se todos os fluxos intermediários de caixa forem reinvestidos à própria TIR calculada. 
Complementarmente, foi calculado o ponto de equilíbrio (lucro econômico zero), o qual se refere ao grau médio anual de utilização da capacidade instalada em que as receitas se igualam ao somatório de custos operacionais e custos imputados aos investimentos, tendo sido arbitrada a taxa de atratividade de $10 \%$ ao ano. Considerando-se que, apesar de superior à taxa do Prodecoop, o horizonte de tempo de 20 anos é superior ao prazo de amortização e o fato de que os empreendimentos devem também exigir recursos próprios.

O ponto de equilíbrio de um projeto indica a quantidade que deve ser produzida e vendida de modo que os custos totais sejam cobertos pelo faturamento (ABREU FILHO et al., 2006, p. 95). Na perspectiva econômica, operar no ponto de equilíbrio significa obter um lucro igual a zero, que é considerado normal pela teoria microeconômica (PINDYCK; RUBINFELD, 1994), pois todos os fatores de produção (inclusive o capital e o empresário) são remunerados segundo seus custos de oportunidade. Sua principal aplicação é orientar quanto à escala mínima de produção que a empresa deve operar. É um indicador compatível com o VPL, pois este é zero quando se opera do ponto de equilíbrio econômico.

Como os pequenos produtores de maçã da região serrana catarinense não dispõem de recursos financeiros para investimento, o estudo de viabilidade econômica foi acrescido da análise financeira relativa a empréstimo bancário para os empreendimentos. Para tanto, foi feita análise da capacidade de solvência dos empreendimentos, admitindo-se o seu financiamento pelo Programa Prodecoop do BNDES, com juros anuais de $6,75 \%$, carência de três anos (quanto ao principal) e amortização em 12 anos.

Como etapa final da metodologia, o estudo foi apresentado a técnicos, dirigentes de cooperativas e autoridades públicas da região serrana, obtendo-se sua concordância quanto aos procedimentos, parâmetros e resultados. 


\section{Resultados e discussão}

\subsection{Número, tamanho e localização dos empreendimentos}

O estudo apontou para a necessidade de investimentos em estrutura de armazenagem de 100 mil toneladas, divididos em duas etapas iguais de 50 mil toneladas. A proposta de localização e tamanho das unidades de armazenagem e classificação de maçã é apresentada na Tabela 1.

Tabela 1: Proposta de localização e tamanho das unidades de armazenagem e classificação de maçã para a região serrana de Santa Catarina

\begin{tabular}{c|c|c|c|c}
\hline \multirow{2}{*}{ Município } & \multirow{2}{*}{ Produção $(\mathrm{t})$} & \multirow{2}{*}{$\begin{array}{c}\text { Capacidade Atual de } \\
\text { Armazenagem }(\mathrm{t})\end{array}$} & \multicolumn{2}{|c}{$\begin{array}{c}\text { Proposta de Ampliação de } \\
\text { Armazenagem }(\mathrm{t})\end{array}$} \\
\cline { 4 - 5 } & & & $1^{\mathrm{a}}$. Etapa & $2^{\mathrm{a}}$. Etapa \\
\hline Bom Jardim da Serra & 41.560 & 8.280 & 10.000 & 10.000 \\
Bom Retiro & 42.000 & 14.755 & - & 10.000 \\
Urubici & 27.380 & 8.430 & - & 10.000 \\
Rio Rufino & 8.040 & 0 & - & - \\
Urupema & 16.000 & 1.400 & 10.000 & - \\
São Joaquim & 160.000 & 79.460 & 30.000 & 20.000 \\
\hline Total & 294.980 & 112.325 & 50.000 & 50.000 \\
\hline
\end{tabular}

Fonte: EPAGRI (2008) e pesquisa de campo (2008).

Justifica-se a alocação de $50 \%$ do investimento no município de São Joaquim pelo maior excedente absoluto de produção local em relação à capacidade de armazenagem (aproximadamente 80.000 t/ano), pela presença de um grande número de pequenos pomicultores, localização estratégica do município, experiência da região na produção de maçã e representatividade produtiva com quase cinco mil hectares ocupados com o cultivo de maçã (EPAGRI, 2008). 


\subsection{Investimentos, preços e custos}

Os principais itens de investimento para os três tamanhos de unidade de armazenamento e classificação de maçã (T1, T2 e T3) são apresentados na Tabela 2. Deve-se registrar que a distribuição do investimento ao longo do tempo para um horizonte de planejamento de 20 anos, além dos investimentos iniciais (ano zero) leva em consideração a necessidade de reposição de automóveis (a cada cinco anos) e de empilhadeiras (a cada 10 anos). Além disso, ao final do período de 20 anos, subsiste o valor residual correspondente a $50 \%$ dos investimentos em obras civis.

Tabela 2: Discriminação e valor ( $\mathrm{R} \$$ mil) dos itens que compõem o investimento inicial

\begin{tabular}{c|c|c|c}
\hline \multirow{2}{*}{ Discriminação } & \multicolumn{3}{|c}{ Valor do Investimento (R \$ mil) } \\
\cline { 2 - 4 } & $\mathrm{T} 1$ & $\mathrm{~T} 2$ & $\mathrm{~T} 3$ \\
\hline Câmaras frias & $6.195,60$ & $12.391,60$ & $18.586,80$ \\
Obras civis para câmaras & $2.524,79$ & $5.049,59$ & $7.574,38$ \\
Máquina de classificação & 710,82 & $1.580,12$ & $2.065,23$ \\
Packing house - obras & $1.578,20$ & $1.984,01$ & $2.389,82$ \\
civis & $1.462,96$ & $2.971,41$ & $4.388,57$ \\
Bins & 350,00 & 550,00 & 700,00 \\
Subestação elétrica & 201,00 & 335,00 & 469,00 \\
Empilhadeiras) & 64,20 & 80,25 & 101,65 \\
Prédio da administração & 45,00 & 45,00 & 45,00 \\
Balança & 74,00 & 96,00 & 118,00 \\
Automóveis) & 11,70 & 14,60 & 19,00 \\
Móveis e utensílios & 749,68 & $1.499,31$ & $2.248,94$ \\
Capital de giro & $\mathbf{1 3 . 9 6 7 , 9 5}$ & $\mathbf{2 6 . 5 9 6 , 8 9}$ & $\mathbf{3 8 . 7 0 6 , 3 9}$ \\
\hline TOTAL & & & \\
\hline Valor Residual dos & $2.051,50$ & $3.516,80$ & $4.982,10$ \\
Investimentos &
\end{tabular}

Fonte: Elaboração própria com base na pesquisa de campo (2008).

Notas: 1) Reposição no ano 10; 2) Reposição nos anos 5, 10 e 15.

Como já referido na seção anterior, os valores de referência usados nas estimativas de custos são originários da experiência e da prática atual da Cooperserra, que possui uma unidade industrial com capacidade de produção de 20 mil t/ano. Com o aumento da escala, estes custos também aumentam, embora de forma tênue, admitindo-se assim a ocorrência de fracas economias de escala. Os principais custos fixos "no curto prazo" 
estão relacionados ao pessoal administrativo, manutenção, despesas administrativas e combustíveis, totalizando para as escalas T1, T2 e T3, respectivamente, $\mathrm{R} \$ 488,20, \mathrm{R} \$ 654,00$ e $\mathrm{R} \$ 835,00$ anuais.

Os principais elementos dos custos variáveis por tonelada, de acordo com a Cooperserra para o ano de 2008, são: matéria-prima maçã (R\$ $540,00)$, embalagens ( $\mathrm{R} \$ 172,22)$, pessoal de produção ( $\mathrm{R} \$ 118,40)$, energia elétrica $(R \$ 36,00)$, insumos químicos $(R \$ 17,50)$ e água $(R \$$ $3,24)$. O Custo Variável Médio (CVMe) resultante é R $\$ 0,9148 / \mathrm{kg}$.

Para estimativa da receita, considerou-se o preço médio na região de São Joaquim pago pelas empresas aos produtores não cooperados nas safras de 2006, 2007 e 2008, acrescidos de 3\% de quebra de peso. Assim, o preço médio de venda da maçã classificada e embalada na saída da indústria é R\$ 1,2834 por quilo, valor obtido com base na experiência da Cooperserra, resultante da ponderação de preços por variedade e categoria do produto. Todos os preços utilizados foram assumidos já como líquidos de impostos indiretos; da mesma forma, os resultados econômico-financeiros dos empreendimentos são valores anteriores à tributação direta, uma vez que as cooperativas distribuem os resultados aos cooperados.

\subsection{Análise econômico-financeira}

Dados o montante e a distribuição dos investimentos ao longo da vida útil dos empreendimentos, bem como os custos fixos anuais, os custos variáveis por tonelada processada e assumindo normalidade de preços, foram calculados o Valor Presente Líquido (VPL) e a Taxa Interna de Retorno anual (TIR). Os resultados indicam VPLs positivos para ocupação da capacidade instalada de $60 \%$ ou acima, apontam também para taxas de retorno acima de $16 \%$ para níveis de ocupação da capacidade de $80 \%$ e acima de $10 \%$ para uma ocupação de $60 \%$ (Tabela 3). Mostram também taxas de retorno superiores para os empreendimentos de maior tamanho, associadas a algumas economias de escala. 
Foram também calculadas as TIR, para os três tamanhos de unidade e diferentes taxas de ocupação da capacidade, utilizando preços de matériaprima e produto no nível de $20 \%$ abaixo da média, mantidos os demais valores (custos e investimentos) constantes. Ou seja, os preços da maçã e da matéria-prima utilizados foram, respectivamente, $\mathrm{R} \$ 1,02672 /$ $\mathrm{kg}$ e $\mathrm{R} \$ 0,432 / \mathrm{kg}$. Em função da queda no preço da matéria-prima, o custo variável caiu para $\mathrm{R} \$ 0,80346 / \mathrm{kg}$. Os resultados evidenciam que a taxa de retorno é mais sensível à queda de preços do que ao nível de ocupação da capacidade e que uma queda nos preços de $20 \%$ em relação à média dos anos de 2006, 2007 e 2008 somente seria suportada pelos empreendimentos se o grau de ocupação da capacidade produtiva fosse de no mínimo $80 \%$.

Tabela 3: Valor presente líquido e taxa interna de retorno anual para as três escalas de produção, em diferentes taxas de ocupação da capacidade instalada e diferentes níveis de preços da maçã e insumos

\begin{tabular}{c|c|c|c|c|c|c|c|c|c}
\hline \multirow{2}{*}{$\begin{array}{c}\text { Capacidade } \\
\text { ocupada (\%) }\end{array}$} & \multicolumn{3}{|c|}{$\begin{array}{c}\text { VPL para Preço Normal } \\
\text { (k=10\% a.a.) }\end{array}$} & \multicolumn{3}{c|}{ TIR (\%) para Preço } & \multicolumn{3}{c}{ TIR (\%) para Preço } \\
\cline { 2 - 9 } & T1 & T2 & T3 & T1 & T2 & T3 & T1 & T2 & T3 \\
\hline \multirow{2}{*}{100} & $13.391,97$ & $30.871,22$ & $48.740,56$ & 22,45 & 24,93 & 26,12 & 11,02 & 13,18 & 14,11 \\
80 & $7.115,78$ & $18.318,82$ & $29.911,90$ & 16,82 & 19,11 & 20,16 & 7,08 & 8,82 & 10,08 \\
60 & 839,58 & $5.766,43$ & $11.083,30$ & 10,84 & 12,99 & 13,93 & 2,65 & 4,82 & 5,66 \\
40 & $-5.436,62$ & $-6.785,97$ & $-7.745,29$ & 4,07 & 6,21 & 7.05 & $-2,73$ & $-0,34$ & 0,51 \\
\hline
\end{tabular}

Fonte: Elaboração própria com base na pesquisa de campo (2008).

Ainda para avaliar o risco da viabilidade do projeto em função de oscilações nos preços de venda da maçã, foram obtidos valores de VPL para as três escalas de produção operando com $80 \%$ de sua plena capacidade (Figura 1). Os dados revelam que o VPL se torna positivo quando os preços de venda da maçã assumem valores de 1,14; 1,15 e $1,18 \mathrm{R} \$ / \mathrm{kg}$, para as escalas T3, T2 e T1, respectivamente. 


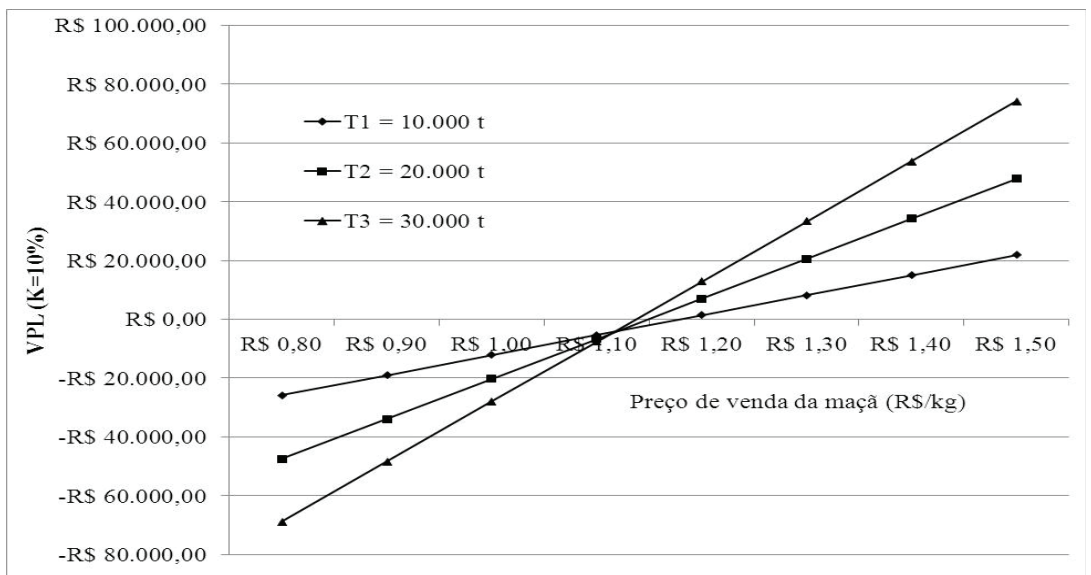

Figura 1: VPL segundo oscilações de preços da maçã para as três escalas de operação

Fonte: Elaboração própria com base na pesquisa de campo (2008).

A Figura 2 mostra que o empreendimento T1, com capacidade de processamento de $10 \mathrm{mil}$ t/ano, tem seu ponto de equilíbrio, nas condições previstas de preço e produtividade, com a utilização de $57 \%$ de sua capacidade produtiva instalada. Este resultado foi obtido considerando-se custos fixos da ordem de R $\$ 2.100$ mil, custos variáveis por tonelada de $\mathrm{R} \$ 914,80$, preço de venda à indústria de $\mathrm{R} \$ 1.283,40 /$ t e custo imputado aos capitais investidos de $10 \%$ a.a. Os mesmos procedimentos foram feitos para os investimentos de maior escala, em que o empreendimento T2, de 20 mil t/ano, tem seu ponto de equilíbrio com 51\% de utilização de sua capacidade instalada, enquanto o empreendimento T3, de 30 mil t/ano, alcança equilíbrio econômico utilizando apenas 43\% da capacidade instalada, nas condições correntes (médias) de preços. 


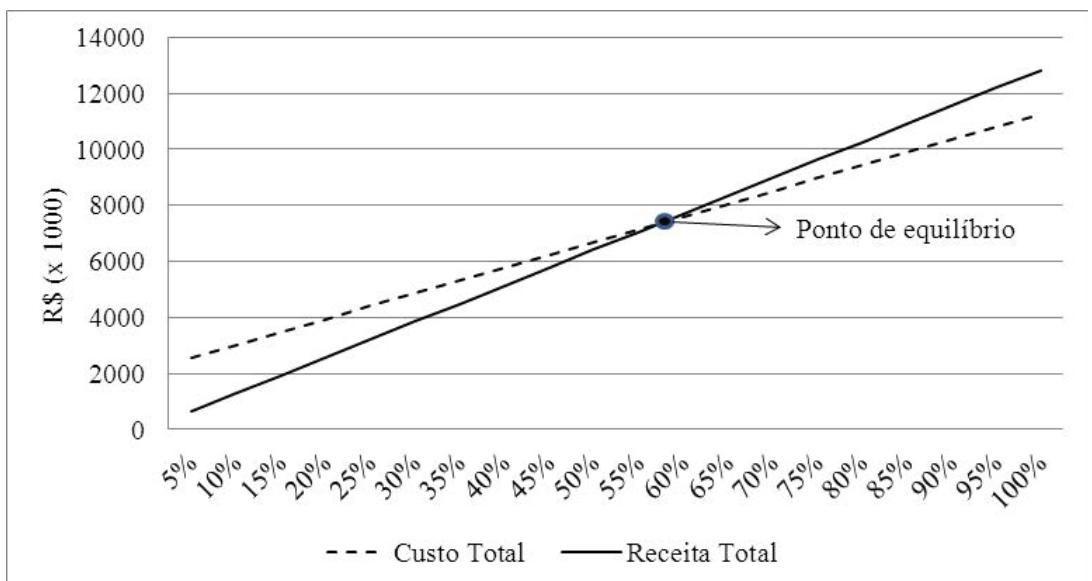

Figura 2: Ponto de equilíbrio para a capacidade instalada de 10 mil toneladas anuais

Fonte: Elaboração própria com base na pesquisa de campo (2008).

Em resumo, essas análises evidenciam que os empreendimentos apresentam indicadores de significativa viabilidade econômica em períodos normais de operação, devendo ser destacadas duas fontes potenciais de instabilidade: a ociosidade elevada das unidades industriais motivada pela produção insuficiente dos produtores cooperados e a queda no preço da maçã no mercado brasileiro. Embora as taxas de retorno dos empreendimentos sejam mais sensíveis ao preço que à quantidade, os novos empreendimentos são tomadores de preço, uma vez que o mercado da maçã pode ser considerado "competitivo". Por isso, os esforços principais devem se dirigir a congregar um contingente suficiente de produtores para garantir o abastecimento adequado das novas unidades para reduzir o impacto de quedas de preço.

A análise da viabilidade financeira dos empreendimentos toma por base, além dos parâmetros de preço e custos já detalhados anteriormente, a opção de financiamento pelo Prodecoop do BNDES, que financia, em até $90 \%$, projetos de cooperativas à taxa nominal de $6,75 \%$ a.a. com três anos de carência. Para tanto, foram construídos fluxos de caixa 
para os três tamanhos de empreendimento, assumindo operação a 80\% da capacidade instalada e diferentes porcentagens de financiamento do investimento (Tabelas 5, 6 e 7).

Tabela 5: Fluxo de caixa do empreendimento T1 (em mil R\$) a diferentes percentuais de financiamento* e assumindo grau de utilização da capacidade instalada de $80 \%$

\begin{tabular}{c|c|c|c|c|c|c|c}
\hline \multirow{2}{*}{ Anos } & \multirow{2}{*}{$\begin{array}{c}\text { Resultado } \\
\text { Operacional } \\
\text { (mil R\$) }\end{array}$} & \multicolumn{2}{|c|}{$90 \%$} & \multicolumn{2}{|c}{$70 \%$} & \multicolumn{2}{c}{$50 \%$} \\
\cline { 3 - 8 } & & Prestação & Saldo & Prestação & Saldo & Prestação & Saldo \\
\cline { 3 - 8 } & - & - & $-1.396,80$ & - & $-4.190,39$ & - & $-6.983,98$ \\
1 a 3 & $2.460,60$ & 848,55 & $1.612,05$ & 659,99 & $1.800,61$ & 471,42 & $1.989,18$ \\
4 & $2.460,60$ & $1.909,03$ & 551,57 & $1.484,80$ & 975,80 & 1060,57 & $1.400,03$ \\
5 & $2.386,60$ & $1.909,03$ & 477,57 & $1.484,80$ & 901,80 & 1060,57 & $1.326,03$ \\
6 a 9 & $2.460,60$ & $1.909,03$ & 551,57 & $1.484,80$ & 975,80 & 1060,57 & $1.400,03$ \\
10 & $2.185,60$ & $1.909,03$ & 276,57 & $1.484,80$ & 700,80 & 1060,57 & $1.125,03$ \\
11 e 12 & $2.460,60$ & $1.909,03$ & 551,57 & $1.484,80$ & 975,80 & 1060,57 & $1.400,03$ \\
13 e 14 & $2.460,60$ & - & $2.460,60$ & - & $2.460,60$ & - & $2.460,60$ \\
15 & $2.386,60$ & - & $2.386,60$ & - & $2.386,60$ & - & $2.386,60$ \\
\hline
\end{tabular}

Fonte: Elaboração própria com base na pesquisa de campo (2008).

Nota: *Taxa nominal de juros de $6,75 \%$ a.a.

Observando-se o fluxo de caixa anual para o empreendimento T1, cujo investimento inicial é da ordem de R $\$ 13.967$ mil, conforme a Tabela 5 , os números revelam que não ocorreriam dificuldades financeiras nos 12 primeiros anos de pagamento do empréstimo, independentemente da fração do capital que for financiada. Além disso, se obtido o financiamento pelo Prodecoop, o capital próprio restante teria perspectiva de elevada rentabilidade de $24 \%, 35 \%$ e $106 \%$, respectivamente, se 
o capital próprio financiar $50 \%, 30 \%$ ou $10 \%$ do empreendimento. Resulta, então, que, do ponto de vista dos produtores empreendedores, é vantajoso obter a maior participação possível do Prodecoop no empreendimento. Entretanto, simulação adicional feita para a hipótese de ocorrência do cenário negativo de queda de preços de $20 \%$ (do produto e da matéria-prima), e operando a $80 \%$ da capacidade plena, indica que o empreendimento enfrentaria dificuldades financeiras durante os anos de amortização do empréstimo se financiar o valor de $90 \%$ ou $70 \%$ do investimento.

Tabela 6: Fluxo de caixa do empreendimento T2 (em mil R\$) a diferentes percentuais de financiamento* e assumindo grau de utilização da capacidade instalada de $80 \%$

\begin{tabular}{|c|c|c|c|c|c|c|c|}
\hline \multirow{3}{*}{ Anos } & \multirow{3}{*}{$\begin{array}{l}\text { Resultado } \\
\text { Operacional } \\
\text { (mil R\$) }\end{array}$} & \multicolumn{6}{|c|}{ Percentual do Investimento Financiado } \\
\hline & & \multicolumn{2}{|c|}{$90 \%$} & \multicolumn{2}{|c|}{$70 \%$} & \multicolumn{2}{|c|}{$50 \%$} \\
\hline & & Prestação & Saldo & Prestação & Saldo & Prestação & Saldo \\
\hline 0 & - & - & $-2.659,69$ & - & $-7.979,07$ & - & $-13.298,45$ \\
\hline 1 a 3 & $5.243,60$ & $1.795,29$ & $3.448,31$ & $1.256,70$ & $3.986,90$ & 897,65 & $4.345,95$ \\
\hline 4 & $5.243,60$ & $4.038,96$ & $1.204,64$ & $2.827,27$ & $2.416,33$ & $2.019,48$ & $3.224,12$ \\
\hline 5 & $5.147,60$ & $4.038,96$ & $1.108,64$ & $2.827,27$ & $2.320,33$ & $2.019,48$ & $3.128,12$ \\
\hline 6 a 9 & $5.243,60$ & $4.038,96$ & $1.204,64$ & $2.827,27$ & $2.416,33$ & $2.019,48$ & $3.224,12$ \\
\hline 10 & $4.812,60$ & $4.038,96$ & 773,64 & $2.827,27$ & $1.985,33$ & $2.019,48$ & $2.793,12$ \\
\hline 11 e 12 & $5.243,60$ & $4.038,96$ & $1.204,64$ & $2.827,27$ & $2.416,33$ & $2.019,48$ & $3.224,12$ \\
\hline 13 e 14 & $5.243,60$ & - & $5.243,60$ & - & $5.243,60$ & - & $5.243,60$ \\
\hline 15 & $5.147,60$ & - & $5.147,60$ & - & $5.147,60$ & - & $5.147,60$ \\
\hline 16 a 20 & $5.243,60$ & - & $5.243,60$ & - & $5.243,60$ & - & $5.243,60$ \\
\hline \multicolumn{3}{|c|}{$\begin{array}{c}\text { Taxa de retorno sobre o capital } \\
\text { próprio }\end{array}$} & $121,85 \%$ & - & $43,58 \%$ & - & $29,09 \%$ \\
\hline
\end{tabular}

Fonte: Elaboração própria com base na pesquisa de campo (2008).

Nota: *Taxa nominal de juros de $6,75 \%$ a.a. 
Tabela 7: Fluxo de caixa do empreendimento T3 (em mil R\$) a diferentes percentuais de financiamento* assumindo grau de utilização da capacidade instalada de $80 \%$

\begin{tabular}{|c|c|c|c|c|c|c|c|}
\hline \multirow{3}{*}{ Anos } & \multirow{3}{*}{$\begin{array}{l}\text { Resultado } \\
\text { Operacional } \\
\text { (mil R\$) }\end{array}$} & \multicolumn{6}{|c|}{ Percentual do Investimento Financiado } \\
\hline & & \multicolumn{2}{|c|}{$90 \%$} & \multicolumn{2}{|c|}{$70 \%$} & \multicolumn{2}{|c|}{$50 \%$} \\
\hline & & Prestação & Saldo & Prestação & Saldo & Prestação & Saldo \\
\hline 0 & 0 & - & $-3.870,64$ & - & $-11.611,92$ & - & $-19.353,20$ \\
\hline 1 a 3 & $8.011,40$ & $2.351,41$ & $5.659,99$ & $1.828,88$ & $6.182,52$ & $1.306,34$ & $6.705,06$ \\
\hline 4 & $8.011,40$ & $5.290,09$ & $2.721,31$ & $4.114,52$ & $3.896,88$ & $2.938,94$ & $5.072,46$ \\
\hline 5 & $7.893,40$ & $5.290,09$ & $2.603,31$ & $4.114,52$ & $3.778,88$ & $2.938,94$ & $4.954,46$ \\
\hline 6 a 9 & $8.011,40$ & $5.290,09$ & $2.721,31$ & $4.114,52$ & $3.896,88$ & $2.938,94$ & $5.072,46$ \\
\hline 10 & $7.424,40$ & $5.290,09$ & $2.134,31$ & $4.114,52$ & $3.309,88$ & $2.938,94$ & $4.485,46$ \\
\hline 11 e 12 & $8.011,40$ & $5.290,09$ & $2.721,31$ & $4.114,52$ & $3.896,88$ & $2.938,94$ & $5.072,46$ \\
\hline 13 e 14 & $8.011,40$ & - & $8.011,40$ & - & $8.011,40$ & - & $8.011,40$ \\
\hline 15 & $7.893,40$ & - & $7.893,40$ & - & $7.893,40$ & - & $7.893,40$ \\
\hline 16 a 20 & $8.011,40$ & - & $8.011,40$ & - & $8.011,40$ & - & $8.011,40$ \\
\hline \multicolumn{3}{|c|}{$\begin{array}{l}\text { Taxa de retorno sobre o capital } \\
\text { próprio }\end{array}$} & $140,73 \%$ & - & $47,27 \%$ & - & $31,20 \%$ \\
\hline
\end{tabular}

Fonte: Elaboração própria com base na pesquisa de campo (2008).

Nota: *Taxa nominal de juros de $6,75 \%$ a.a.

Os resultados financeiros projetados para os dois outros empreendimentos (T2 e T3) são melhores em virtude do melhor desempenho operacional (Tabelas 6 e 7). Os dois empreendimentos, T2 e T3, que exigem um investimento inicial na ordem de R\$ 26.596 mil e R\$ 38.706 mil, respectivamente, não enfrentariam dificuldades de solvência em condições normais de mercado e ocupação de capacidade. Entretanto, de forma semelhante ao empreendimento $\mathrm{T} 1$, a simulação para a hipótese de ocorrer cenário desfavorável de queda de $20 \%$ nos preços, o empreendimento $\mathrm{T} 2$ teria dificuldades financeiras somente se financiar 90\% do capital, enquanto o empreendimento de tamanho T3 ainda teria condições de equilíbrio de caixa no cenário negativo de preços, desde que não esteja combinado com cenário ruim de produção, como uma quebra de safra. 
Neste contexto, as análises mostram que os empreendimentos apresentam indicadores de viabilidade econômica com taxa interna de retorno entre 15 e $20 \%$ e condições de solvência financeira dentro das condições oferecidas pelo Programa Prodecoop, em períodos normais de operação em termos de produção agrícola e mercado consumidor. Podem-se, entretanto, antever problemas de solvência na hipótese de cenários negativos de produção (quebra de safra e/ou não entrega de produto) e de mercado (queda de preço), em face da falta de capacidade de alavancagem de recursos por parte dos pequenos produtores de maçã cooperados. Diante disso, os futuros gestores devem ser alertados e cientes do ciclo natural de mercado de produtos agrícolas, fazendo as devidas reservas financeiras nos anos de preço/produção favorável para suportar as dificuldades nos anos de cenário negativo.

\section{Conclusões}

Buscou-se neste estudo a análise da viabilidade econômico-financeira da implantação de estruturas de armazenagem e seleção de maçã na região serrana catarinense. Evidenciou-se que existe déficit de capacidade de armazenagem, podendo ser programada sua ampliação em $100 \mathrm{mil}$ t, em duas etapas iguais de 50 mil t, em empreendimentos com capacidade de 10 mil, 20 mil e 30 mil t/ano de processamento, com organização na forma de cooperativas de produtores. A análise econômica dos empreendimentos para um horizonte de 20 anos revelou taxas internas de retorno entre 15 e $20 \%$ a.a. para um nível de ocupação da capacidade instalada de $80 \%$ e condições normais de preços de mercado.

As simulações de fluxos de caixa para a hipótese de financiamento parcial dos empreendimentos com recursos do programa Prodecoop (BNDES) apresentam condições de solvência em condições normais de produção e mercado. Entretanto, é destacada a potencialidade de turbulência em cenários negativos de quebra de safra e queda de preços, dada a dificuldade de aportes de recursos pelos cooperados numa eventual necessidade. 
Analisadas as condições de viabilidade econômico-financeira, duas questões relevantes nos campos organizacional e financeiro, que não foram objeto do presente estudo, precisam ser enfrentadas na eventualidade de uma decisão governamental de apoio aos empreendimentos. Na esfera organizacional, evidenciou-se a necessidade de mobilizar produtores, desenvolver competências gerenciais e construir ambiente de confiança favorável aos empreendimentos, uma vez que, diferentemente de outras regiões de Santa Catarina, o local estudado não possui tradição cooperativista. No âmbito financeiro, simulações para cenários desfavoráveis mostraram a necessidade de construir salvaguardas.

\section{Referências}

ABREU FILHO, J. C. F. de; SOUZA, C. P.; GONÇALVES, D. A.; CURY, M. V. Q. Finanças corporativas. Rio de Janeiro: Editora FGV, 2006. $152 \mathrm{p}$.

BARBOSA, L. P.; SIMIONI, F.; CÁRIO, S. A. F. Evolução da produção de maçã em Santa Catarina: novas estratégias em busca da competitividade. In: CONGRESSO BRASILEIRO DE ECONOMIA, ADMINISTRÇÃO E SOCIOLOGIA RURAL, 44., 2006, Fortaleza. Anais... Fortaleza: SOBER, 2006.

\section{BITTENCOURT, C. C. Panorama da cadeia da maçã no estado de} Santa Catarina: uma abordagem a partir dos segmentos da produção e de packing house. Dissertação (Mestrado em Economia). Universidade Federal de Santa Catarina - UFSC: Florianópolis, 2008.

CASAROTTO FILHO, N.; KOPITTKE, B. H. Análise de investimentos: matemática financeira, engenharia econômica, tomada de decisão, estratégia empresarial. São Paulo: Atlas, 2010. 411 p.

EMPRESA DE PESQUISAAGROPECUÁRIA E EXTENSÃO RURAL DE SANTA CATARINA (EPAGRI). Adequação da estrutura de 
armazenagem de maçãs na Região de São Joaquim. São Joaquim: Epagri, 2008. Mimeografado.

GALESNE, A.; FENSTERSEIFER, J. E.; LAMB, R. Decisões de investimentos da empresa. São Paulo: Atlas, 1999.

GUTH, S. C.; MOTTA, M. E. V.; ANDREOLA, J. A. et al. Estudo da viabilidade de reconversão de um pomar de maçã. In: CONGRESSO NACIONAL DE EXCELÊNCIA EM GESTÃO, 6., 2010, Niterói. Anais... Niterói: MSG-UFF/NITS, 2010.

KREUZ, C. L.; SOUZA, A.; PETRI, J. L. Impacto da intensificação da densidade de plantio na rentabilidade em duas cultivares de macieira em Fraiburgo-SC. Revista Brasileira de Fruticultura [online], v. 28, n. 2, p. 240-243, 2006.

KREUZ, C. L.; SOUZA, A.; PETRI, J. L.; CARVALHO JUNIOR, L. C. Análise da rentabilidade da cultura da macieira em duas cultivares e duas densidades de plantio. In: CONGRESSO BRASILEIRO DE ECONOMIA E SOCIOLOGIA RURAL, 43., 2005, Ribeirão Preto. Anais... Ribeirão Preto: SOBER, 2005.

PINDYCK, R. S.; RUBINFELD, D. L. Microeconomia. São Paulo: Makron Books, 1994.

SIMIONI, F. J.; PEREIRA, L. B. Desempenho da produção brasileira e catarinense de maçã: crescimento, concentração e exclusão. In: PEREIRA, L. et al. (Org.). Padrão produtivo e dinâmica econômica competitiva: estudo sobre setores selecionados em Santa Catarina. Florianópolis: Imprensa Universitária da UFSC, 2001. p.187-198.

SIMIONI, F. J.; PEREIRA, L. B. Cadeia agroindustrial da maçã: uma análise da estrutura de governança sob a ótica da economia dos custos de transação. In: CONGRESSO BRASILEIRO DE ECONOMIA E SOCIOLOGIA RURAL, 42., 2004, Cuiabá. Anais... Cuiabá: SOBER, 2004. 